\title{
Moringa oleifera leaves extract regulate the activity of nitric oxide synthases and paraoxonase $I$ in diabetic
}

\section{rat}

\begin{abstract}
This study was aimed at evaluating the effects of $M$. oleifera leaves extract on biochemical physiological parameters, nitric oxide synthase and paraoxonase 1 activities of diabetic model rats. Eighteen Wistar rats were equally split into three groups as follow: control (water), alloxan administration ( $120 \mathrm{mg} / \mathrm{kg} \mathrm{b.w})$, and M. oleifera extract treatment (200 $\mathrm{mg} / \mathrm{kg}$ b.w., daily for twenty-one days), with six rats per group. Glucose, triglycerides, glycated hemoglobin, advanced end products, nitrites were measured in serum. In parallel, nitric oxide synthase (NOS) and paraoxonase 1 (PON1) activities were tested in heart. The results showed that alloxan induces alterations in nitric oxide homeostasis and inhibited the activities of constitutive NOS and PON1, resulting in oxidative stress. While the levels of AGEs and $\mathrm{HbA}_{1 c}$ were elevated in the serum of alloxan-diabetic animals. Oral administration of $M$. oleifera in diabetic animals reduced the glucose, triglycerides, AGEs and HbAlc. In addition, $M$. oleifera treatment significantly rescued the cNOS and PON1 compared to nontreated diabetic group. Surprisingly, we observed a significantly activation of PON1 activity in the $M$. oleifera treatment compared to control group. However, are necessary to further elucidate the activation mechanism. These findings provide a perspective on the cardioprotective effects of diabetic conditions.
\end{abstract}

Keywords: diabetes mellitus, paraoxonase 1, nitric oxide synthase, moringa oleifera, heart
Volume 2 Issue 5 - 2018

\author{
Erick Sierra-Campos,' Mónica A Valdez- \\ Solana,' Jesús R Pérez-Velázquez,' Guadalupe \\ García-Arenas, ${ }^{2}$ Alfredo Téllez-Valencia, ${ }^{3}$ \\ Claudia Avitia-Domínguez ${ }^{3}$ \\ 'Faculty of Chemical Sciences, Juarez University of the State of \\ Durango Campus Gómez Palacio, Mexico \\ ${ }^{2}$ Faculty of Health Sciences, Juarez University of the State of \\ Durango Campus, Mexico \\ ${ }^{3}$ Faculty of Medicine and Nutrition, Juarez University of the \\ State of Durango Campus Durango, Mexico
}

\begin{abstract}
Correspondence: Erick Sierra Campos, University Juarez of Durango State, Av. Articulo $123 \mathrm{~S} / \mathrm{n}$ Fracc. Filadelfia. CP. 35000, Gomez Palacio, Durango, Mexico, Tel +5287 I7I5 8810,
\end{abstract} Email ericksier@gmail.com

Received: October 29, 2018 | Published: November 07, 2018
Abbreviators: $\mathrm{NO}^{*}$, nitric oxide; eNOS, endothelial nitric oxide synthase; iNOS, inducible nitric oxide synthase; $\mathrm{O}_{2}^{--}$, superoxide anion; $\mathrm{Hb}$, hemoglobin; $\mathrm{HbA}_{1 \mathrm{c}}$, glycated hemoglobin; $\mathrm{HbO}_{2}$, oxyhemoglobin; AGEs, advanced glycation products; PON 1, paraoxonase 1; HDL, high density lipoproteins; LDL, low density lipoproteins; NOX2, NADPH oxidase 2; ROS, reactive oxygen species; L-arg, L-arginine; cNOS, constitutive nitric oxide synthase; $\mathrm{BH}_{4}$, tetrahydrobiopterin; $\mathrm{BH}_{3}$, protonated trihydrobiopterin radical cation; $\mathrm{BH}_{2}$, dihydrobiopterin; $\mathrm{ONOO}$, peroxynitrite; $\mathrm{CR}$, red cells

\section{Introduction}

Diabetes mellitus is the major health problem in Mexico. Close to $20 \%$ of the preventable deaths in our country are caused by diabetes and related metabolic diseases. ${ }^{1,2}$ Diabetes mellitus is associated with accelerated atherosclerosis development and with increased risk for cardiovascular disease. Hyperglycemia accelerates atherosclerosis by several mechanisms, including the induction of vascular dysfunction, increasing oxidative stress, increasing lipid peroxidation of lipoproteins and of arterial cells, including macrophages, which may then lead to enhanced macrophage foam cell formation, the hallmark of early atherosclerosis development. ${ }^{3,4}$

It has been well recognized that nitric oxide (NO) is an imperative regulator of the cardiovascular system and is a critical mechanism in preventing the pathogenesis and progression of the cardiovascular complications. ${ }^{5,6}$ In addition, several studies suggest that $\mathrm{NO}$ production is reduced in diabetes and that the decrease of NO may be related to the pathogenesis of diabetic endothelial damage.

NO is synthesized by the members of the NO synthase (NOS) family by the oxidation of L-arginine and NADPH by oxygen to yield L-citruline and NO. ${ }^{7}$ Moreover, NO synthase activity is known to be constitutively low in the normal heart. However, it may dramatically increase when the inducible NO synthase (iNOS) is expressed as in inflammatory reactions or septic shock. ${ }^{8}$ However, it has been reported that diabetes causes a higher expression of iNOS in cardiovascular tissues of diabetic rats. ${ }^{9}$ Therefore, $\mathrm{NO}$ is highly reactive and acts as signaling molecule at low concentration and generates nitrosative stress at high concentration. Thus, both lack and excess of NO production in diabetes can have various important implications on heart function in the body.

The paraoxonases family (PONS, including PON1, PON2 and PON3) are calcium dependent esterases with antioxidant properties, ${ }^{10}$ with enzymatic activities targeted towards a broad range of substrates. Although PONs physiological substrates were not identified yet, several studies showed that PONs are lipo-lactonases, which hydrolyze specific oxidized phospholipids, including products of enzymatic and nonenzymatic oxidation of arachidonic and docosahexaenoic acid, as well as, $\mathrm{N}$-acyl-homoserine lactones and lipo-lactones. Earlies results showing the transfer of PON1 between membranes ${ }^{11}$ and the expression of PON1 in multiple mouse tissues ${ }^{10}$ suggested that PON1 is transferred via HDLs from the liver to tissues where its activity is needed. Hence, inhibition or reduction of PON results in CVD and endothelial cell apoptosis. ${ }^{12}$ Thus, one of the treatment options for preventing CVD and vascular damage due to apoptosis is to elevate PON1 and NOS activities.

Moringa oleifera has been shown to induce cardioprotective mechanism in coronary artery rings. Some et al. ${ }^{13}$ determined the effect of ethanolic and aqueous extract on vascular relaxation in porcine coronary artery rings and showed that Moringa oleifera induce an endothelium dependent and endothelium independent vasorelaxation effect. In addition, several lines of evidence suggest that Moringa fruit inhibits LPS-induced NO/iNOS expression through suppressing the NF- $\mathrm{kB}$ activation in RAW264.7 cells $\mathrm{s}^{14,15}$ and other inflammatory markers such as prostaglandin $\mathrm{E}_{2}$ and interleukins. ${ }^{16}$ However, little is known about the potential role of Moringa oleifera in activation of 
NO synthase. These effects were at least partly mediated through of the eNOS-NO-cGMP pathway. In addition, a recurring explanation for the therapeutic actions of $M$. oleifera medication is the relatively high antioxidant, hypolipidemic and anti-atherosclerotic activities of its leaves, ${ }^{17}$ no data on the effect of this medicinal plant on nitric oxide homeostasis are available. The present study therefore aimed at evaluating the effect of $M$. oleifera leaves extract on the NOS and PON1 activities driving its therapeutic properties in diabetic heart.

\section{Materials and methods}

\section{Preparation of the extract}

The extract was prepared using $23 \mathrm{~g}$ of dry-ground sample and $260 \mathrm{~mL}$ of $80 \%$ methanolic aqueous solution by successive maceration. The mixture was shaken in a magnetic grid at room temperature for $24 \mathrm{~h}$ and then filtered through Whatman filter paper number 1 . The final extract was concentrated on a rotary evaporator, placed in a deep freezer for $24 \mathrm{~h}$ and lyophilized to obtain a powdered extract that was kept at $-80{ }^{\circ} \mathrm{C}$.

\section{Ethics statement}

All experiments were performed in compliance with the guideline for the welfare of experimental animals by the National Institutes of Health and in accordance with the guidelines of Institutional Animal Care. This study was approved by the Institutional Animal Ethics Committee at the Faculty of Health Science, UJED.

\section{Diabetic model and treatment}

Alloxan was dissolved in a citrate buffer $(0.1 \mathrm{M}, \mathrm{pH} 4.5)$ and intraperitoneally injected $(120 \mathrm{mg} / \mathrm{kg})$ to induce diabetes in rats. Rats injected only with citrate buffer served as control. Type 1 diabetes was confirmed evaluating fasting plasma glucose levels after 5 days of induction; the inclusion criteria to establish diabetes were $200 \mathrm{mg} / \mathrm{dL}$ of fasting plasma glucose (Accu-Chek, Germany). Rats were divided in control (C group), diabetic (D group), and M. oleifera-treated diabetic (M group) groups. M group was daily administered with a $200 \mathrm{mg} / \mathrm{kg}$ dose of extract by gavage for 3 weeks, and remaining groups were administered with water as vehicle.

\section{Isolation heart cytosolic fraction}

The hearts were homogenized three times at high speed (Polytron PowerGen model 125 , Fisher Scientific) at $4^{\circ} \mathrm{C}$ in a homogenizing solution for $20 \mathrm{~s}$. The homogenizing solution contained $20 \mathrm{mM}$ Tris$\mathrm{HCl}, 200 \mathrm{mM}$ mannitol, $50 \mathrm{mM}$ sucrose, $1 \mathrm{mM}$ EDTA, $1 \mathrm{mM}$ PMSF, 1 protease inhibitor tablet, and $0.1 \%$ bovine serum albumin (BSA) $(\mathrm{pH}$ 7.4). Cellular and nuclear fractions were removed in the pellet by centrifuging at $3,500 \mathrm{rpm}$ for $10 \mathrm{~min}$ at $4^{\circ} \mathrm{C}$. Mitochondria were obtained by centrifuging the supernatant for $10 \mathrm{~min}$ at $11,000 \mathrm{rpm}$. The supernatant is referred to as the cytosolic fraction.

\section{Determination of PONI lactonase activity}

For the determination of PON1 lactonase activity in serum, 2-dihydroxy-coumarin was used as substrate according to Billecke et al. ${ }^{18}$ with slight modifications. The assay mixture contained $100 \mu \mathrm{L}$ of $10 \mathrm{mmol} / \mathrm{L}$ substrate solution, $5 \mu \mathrm{L}$ of serum and $1 \mathrm{mmol} / \mathrm{L} \mathrm{CaCl}_{2}$ in $50 \mathrm{mmol} / \mathrm{L}$ Tris buffer, $\mathrm{pH}$ 8.0. Product formation was determined spectrophotometrically after $5 \mathrm{~min}$ at $270 \mathrm{~nm}$. Molar extinction coefficient is $876 \mathrm{M}^{-1} \mathrm{~cm}^{-1}$ was used to calculate the rate of hydrolysis. PON1 activity was monitored in triplicate and corrected for the nonenzymatic hydrolysis and the results are presented as $\mathrm{nmol} / \mathrm{min} / \mathrm{mg}$ protein.

\section{NO measurement by Griess reaction}

NO concentration was determined by quantifying the stable endproduct of NO, nitrite. A colorimetric assay based on the Griess reaction was used. Briefly, $80 \mu \mathrm{L}$ of serum of each treatment $(\mathrm{C}, \mathrm{D}$ and $\mathrm{M}$ groups) were sequentially mixed with $80 \mu \mathrm{L}$ of a $1 \%$ solution of sulfanilic acid in $5 \%$ phosphoric acid and $80 \mu \mathrm{L}$ of a $0.1 \%$ solution of $\mathrm{N}$-(1-naphthyl) ethylenediamine dihydrochloride. The mixture was kept at room temperature for $30 \mathrm{~min}$. The absorbance was measured at $550 \mathrm{~nm}$. Nitrite concentrations were calculated from a standard curve obtained by diluting the sodium nitrite stock solution.

\section{AGEs fluorescence measurement}

The formation of total AGEs was assessed by monitoring the production of these fluorescent products of glycated proteins samples and positive control at excitation and emission wavelengths of 370 and $440 \mathrm{~nm}$ respectively on spectrofluorometer. The fluorescence of AGEs was expressed as arbitrary units per protein concentration.

\section{Glycosylated hemoglobin $\left(\mathrm{Hb}_{\mathrm{lc}}\right)$ levels}

Commercial enzyme-linked immunosorbent assay kit was used to quantify glycosylated hemoglobin levels. The analysis was performed in accordance with instructions provided by the manufacturer (Biocompare, USA).

\section{Statistical analysis}

Data obtained from the different experimental groups were compared by one-way ANOVA followed by LSD test for post hoc analysis, using Sigmaplot 12.3 software. Differences with $\mathrm{P}<0.05$ were considered significant. Data are presented as mean \pm SEM.

\section{Results}

Table 1 shows the general parameters of the different experimental groups (control, C; diabetics, D; and diabetics treated with Moringa oleifera extract, M). It is interesting to note that the weight of heart in group D was $50 \%$ less than the weight of the other treatments (C and $\mathrm{M}$ ), which could have negative effects on the functionality of the cardiovascular system. Despite this difference, the body weight of the three treatments only changed slightly, with noticeable different at $\mathrm{M}$ group. In addition, the heart weight/body weight (HW/BW) ratio decreased almost two times in $\mathrm{D}$ group in comparison with $\mathrm{C}$ group, by contrast, $\mathrm{M}$ group resulted in an increased HW/BW ratio in comparison to the $\mathrm{D}$ group. On the other hand, glucose and triglyceride levels were higher in group D compared in the control group. In this regard, group M presented a significant decrease with respect to group $\mathrm{D}$ and its values are closer to those reported in the control group.

Table I General features of experimental rats

\begin{tabular}{llll}
\hline Parameter & C group & D group & M group \\
\hline Body weight $(g)$ & $167.2 \pm 8^{*}$ & $172 \pm 10^{*}$ & $184 \pm 6$ \\
Heart weight $(g)$ & $0.73 \pm 0.06^{*}$ & $0.48 \pm 0.04$ & $0.7 \pm 0.02^{*}$ \\
Heart/BW ratio $(\mathrm{mg} / \mathrm{g})$ & $4.36 \pm 0.16$ & $2.79 \pm 0.2^{* *}$ & $3.8 \pm 0.1^{* *}$ \\
\hline
\end{tabular}

Each value represents mean $\pm \mathrm{SE}$. $* \mathrm{P}<0.05$ level of significance of difference between $D$ group and other groups $(C$ and $M)$. ** $P<0.05$ level of significance of difference between $C$ group and other groups ( $D$ and $M)$. ${ }^{\mathrm{t}} \mathrm{P}<0.05$ level of significance of difference between $M$ group and other groups ( $C$ and $D)$.

Our results showed that levels of glucose and triglycerides increased by 5.2 and 2.6 times, respectively, in the plasma of D group compared to $\mathrm{C}$ group (Table 2). In addition, an expected significant 
difference was observed in plasma $\mathrm{HbA1c}$ levels between D group compared to $\mathrm{C}$ group. Similarly, a significant difference was difference between these two groups was also observed in F-AGEs, as they were significantly increased by 8.5 times in the $\mathrm{D}$ group and they remained unaffected in the $\mathrm{M}$ group. To demonstrate that dysfunction occurred at the level of the vasculature, we performed the measurement of serum nitrites as an indicator of nitric oxide levels. In the Table 2 also shows that the concentrations of nitrites in group $\mathrm{D}$ increased 2 times more than in group $\mathrm{C}$, in contrast, $\mathrm{M}$ group presented a decrease approximately 3 times lower with respect to the value obtained in $\mathrm{D}$ group. In addition, $\mathrm{M}$ group presents the lowest levels of nitrites compared to the other study groups. All these data together indicate that the administration of the diabetic agent modified the metabolism of carbohydrates and lipids; this in turn supports endothelial dysfunction and the appearance of cardiovascular complications. A possible explanation for this behavior could be because M. oleifera extract is very rich in antioxidant compounds that could modify the redox state of nitric oxide. Therefore, the next aim of this study was to quantify the activity of nitric oxide synthases (eNOS and iNOS) present in heat cytosol fraction.

Table 2 Biochemical parameters of experimental groups

\begin{tabular}{llll}
\hline Parameters & C group & D group & M group \\
\hline Plasma glucose $(\mathrm{mg} / \mathrm{dL})$ & $80 \pm 5$ & $415 \pm 26^{* *}$ & $125 \pm 13^{* *}$ \\
Plasma Triglycerides $(\mathrm{mg} / \mathrm{dL})$ & $74 \pm 9$ & $198 \pm 12^{* *}$ & $145 \pm 4^{* *}$ \\
Plasma HbA $_{\mathrm{Ic}}(\%)$ & $6.5 \pm 0.7^{*}$ & $10.4 \pm 2.1$ & $8.3 \pm 3.7^{*}$ \\
F-AGEs (AU/g protein) $\times 10^{5}$ & $0.8 \pm 0.2^{*}$ & $6.8 \pm 1.2$ & $1.7 \pm 0.5^{*}$ \\
Serum nitrites levels (Ppm) & $5.66 \pm 0.8^{*}$ & $10.89 \pm 0.3^{* * *}$ & $2.74 \pm 0.5^{* *}$ \\
\hline
\end{tabular}

Each value represents mean $\pm \mathrm{SE}$. $* \mathrm{P}<0.05$ level of significance of difference between $D$ group and other groups $(C$ and $M)$. ${ }^{*} P<0.05$ level of significance of difference between $C$ group and other groups ( $D$ and $M$ ). ${ }^{\mathrm{t}} \mathrm{P}<0.05$ level of significance of difference between $M$ group and other groups ( $C$ and $D)$.

Table 3 Heart nitric oxide synthase activity

\begin{tabular}{|c|c|}
\hline Groups & $\begin{array}{l}\text { Basal activity (nmol/ } \\
\mathrm{min} / \mathrm{mg} \text { protein) }\end{array}$ \\
\hline $\mathrm{C}$ & $1.4 \pm 0.3$ \\
\hline $\mathrm{D}$ & $12 \pm 4.8$ \\
\hline$M$ & $0.8 \pm 0.6$ \\
\hline \multicolumn{2}{|c|}{$\begin{array}{l}\text { Activation of eNOS activity by } \\
\mathrm{BH}_{4}+\text { calmodulin }\end{array}$} \\
\hline C & $7.2 \pm 1.8^{i}$ \\
\hline $\mathrm{D}$ & $10.6 \pm 2.1^{* *_{t}}$ \\
\hline$M$ & $4.5 \pm 0.7^{* *}$ \\
\hline
\end{tabular}

Each value represents mean \pm SE. $* * P<0.05$ level of significance of difference between $C$ group and other groups ( $D$ and $M)$. ${ }^{\mathrm{P}} \mathrm{P}<0.05$ level of significance of difference between $M$ group and other groups ( $C$ and $D)$.

Table 4 Serum paraoxonase I activity

\begin{tabular}{llll}
\hline & C group & D group & M group \\
\hline PONI activity (nmol/ & $65.83 \pm 8.9 \div$ & $43.2 \pm 3.5 * * *$ & $107.4 \pm 7.9 * *$ \\
min/mg protein) & & & \\
\hline
\end{tabular}

Each value represents mean $\pm \mathrm{SE}$. $* * \mathrm{P}<0.05$ level of significance of difference between $C$ group and other groups $(D$ and $M)$. ${ }^{\mathrm{t}}<0.05$ level of significance of difference between $M$ group and other groups ( $C$ and $D)$.

Similarly, to the results of Table 2, the M group presented the lowest activity values, which correlates with the fact that the nitrite levels are derived from the activity of the NOS and not from other intracellular sources (Table 3). It is important to note that D group has the highest NOS activity, which corresponds 10times more than $\mathrm{C}$ group. As the different isozymes of NO synthase are characterized by their dependence on calcium/calmodulin and by their sensitivity to $\mathrm{BH}_{4}$. Basal NO activity was first measured in homogenates prepared from hearts. The activity in the presence of a saturating concentration of $\mathrm{BH}_{4}$ and calmodulin was $7.2 \pm 1.8 \mathrm{nmol} / \mathrm{min} / \mathrm{mg}$ protein in $\mathrm{C}$ group. One possible explanation is that during the development of the pathology the expression and activity of the iNOS significantly increases and by on the other hand, the eNOS tends to be uncoupled, which causes the appearance of an oxidative or nitrosative stress. To assess the previous hypothesis, the cytosolic fractions of each treatment were incubated in the presence of $\mathrm{BH}_{4}$ and calmodulin to favor the activity of the eNOS. It was observed that the addition of both $\mathrm{BH}_{4}$ and calmodulin favors that the NOS values increase in $\mathrm{C}$ and $\mathrm{M}$ groups. In contrast, D group does not modify its NOS activity due to the presence of these substrates, which suggests that this activity is of the iNOS while in the other groups $(\mathrm{C}$ and $\mathrm{M})$, its activity derives mainly from a constitutive NOS that depends on $\mathrm{BH}_{4}$ and $\mathrm{CaM}$ (Table $3)$.

The fact that group $\mathrm{C}$ and $\mathrm{M}$ had a positive effect when adding $\mathrm{BH} 4$ and Calmodulin suggests that this condition may favor oxidative stress in the vasculature. In addition, the high activity of the NOSi observed in group $\mathrm{D}$ is consistent with the idea that in this pathology a moderate inflammatory process occurs which favors lipid lipoperoxidation and considering the elevated levels of triglycerides observed in Table 2 propose the measurement of a lipoprotein biomarker of its oxidation in the bloodstream. Therefore, in Table 4, it is observed that the activity of paraxonase 1 (PON1) in D group decreased slightly significantly with respect to $\mathrm{C}$ group. To our surprise, $\mathrm{M}$ group showed an almost double increase in PON 1 activity with respect to $\mathrm{C}$ group. These results suggest that $M$. oleifera not only protects the activity of PON 1 but also activates it. However, the activation mechanism is in the study stage. Each value represents mean \pm SE. $* * \mathrm{P}<0.05$ level of significance of difference between $\mathrm{C}$ group and other groups (D and M). ${ }^{\mathrm{P}} \mathrm{P}<0.05$ level of significance of difference between $\mathrm{M}$ group and other groups (C and D).

\section{Discussion}

Under high glucose conditions, vascular endothelial cells generate high levels of ROS, inflammatory markers and have impaired nitric oxide biosynthesis. Together these factors result in an imbalance between vasoconstriction and vasodilation, as well as an inability to regulate vascular tone characterizing endothelial dysfunction, the hallmark of diabetes. ${ }^{19}$ It has been reported that diabetes causes a higher expression of cardiac nitric oxide synthases. ${ }^{20}$ These enzymes are responsible of producing $\mathrm{NO}$ in the heart, being essential for heart homeostasis and mechanical activity. ${ }^{21}$ The enhancement in NO production could be associated with nitration of cytoskeletal proteins, leading to alterations in cardiac contractility. ${ }^{22}$ In diabetic hearts, the NOS activity inhibition by L-NMMA or L-NAME, improves cardiac activity, suggesting that both $\mathrm{NO}$ and peroxynitrite $\left(\mathrm{ONOO}^{-}\right)$could be associated with the inhibition of cardiac contractility. ${ }^{23}$

Our result tends to support that advanced glycation end-products (AGEs) and their signal-transducing receptor interactions induce the formation of ROS, leading to concomitant oxidative stress and vascular inflammation, thereby playing a central role in the pathogenesis of various vascular complications in diabetes. ${ }^{24}$ Several studies strongly suggest that glycation of circulating proteins plays a critical and causative role in the pathogenesis of diabetes. ${ }^{25}$ Since 
circulating erythrocytes (Red cells) are continuously interacting with glycated albumin during hyperglycemic conditions. During circulation, the interaction of glycated albumin with erythrocytes causes cell aggregation ${ }^{26}$ and subsequently induce oxidative stress in vessel wall resulting in the development of diabetic complications. ${ }^{27}$ Thus, erythrocytes are important in orchestrating the toxic effects of glycated albumin. High glucose leading to increased ROS-induced oxidative stress through PKC-dependent activation of NADPH oxidase in vascular endothelial cells plays a central role in the onset of diabetic micro- and macrovascular disorders. ${ }^{28}$ In addition, inducible $\mathrm{NO}$ synthase (iNOS) expression and $\mathrm{ONOO}^{-}$radical formation are significantly increased in diabetic vascular tissues. ${ }^{29}$ However, other have found no effect $^{30}$ or decreased iNOS expression in vascular smooth muscle cells (VSMC).$^{31}$ As reported by Pacheco et al. ${ }^{32}$ high glucose levels increase the induction of iNOS and the subsequent NO production, through the activation of the PKC- $\beta$ II isoform in VSMC from normotensive but not from hypertensive rats.

Normally tetrahydrobiopterin $\left(\mathrm{BH}_{4}\right)$ is a cofactor of $\mathrm{NO}$ synthase (NOS) that is required for NO production from endothelial NOS (eNOS) and neuronal NOS (nNOS). A lack of $\mathrm{BH}_{4}$ leads to eNOS uncoupling and then generation of superoxide anion $\left(\mathrm{O}_{2}{ }^{-}\right)$, by a mechanism generally attributed to the oxidation of $\mathrm{BH}_{4}$ to $\mathrm{BH}_{2}$ by $\mathrm{ONOO}^{-}$formed from the near diffusion rate reaction between $\mathrm{O}_{2}-$ and NO. This accumulation of $\mathrm{BH}_{2}$ is sufficient to displace $\mathrm{BH}_{4}$ from eNOS, resulting in uncoupling of the enzyme at the heme group within the oxygenase domain. ${ }^{33}$ Several studies suggest that diabetes induces alterations of calcium handling and impairs NO formation in coronary endothelial cells, due to $\mathrm{BH}_{4}$ deficiency, and in the contractile proteins that limit myocardial function independent of altered metabolism. ${ }^{34,35}$ According to the present results, it can be deduced that M. oleifera extract inhibits the uncoupling of NOS activity and iNOS upexpression induced by hyperglycemia (Table 4).

The paraoxonase (PON1) is the most studied enzyme of the family. It is synthesized primarily in the liver and appears mainly in serum, where is a mostly bound to high-density lipoprotein particle (HDL), that has antioxidant and anti-inflammatory activities. ${ }^{36}$ While that PON2 is located intracellular and PON3, although appears also in serum, is around 2 orders of magnitude less abundant that PON1. ${ }^{37}$ An inverse relationship between PON1 activity and inflammatory responses has been described in numerous experimental models and clinical conditions, such as cardiovascular disease, ${ }^{38}$ diabetes, ${ }^{39}$ hypercholesterolemia, ${ }^{40}$ and parasite infection. ${ }^{41}$ Therefore, low levels of PON1 have been associated with the development of several pathological conditions, whereas high levels have been shown to be anti-atherosclerotic in mouse models. To our best knowledge, no information concerning effect of M. oleifera on PON1 activity has been published. Hence, it can be deduced that major constituents of $M$. oleifera leaves extract are capable of binding to PON1 leads to increase in maximal velocity of the reaction and/or a decrease in substrate affinity. Thus, our results tend to support a previous study by Atrahimovich et al. ${ }^{42}$ which shown that the polyphenols, such as quercetin, bind to an allosteric site on recombinant PON1 and affect the enzyme function and biology.

Taken together, we proposed a model to explain our results. The alloxan administration causes hyperglycemia that provokes an osmotic stress on red cells causes' hemolysis and hemoglobin release. Posteriorly, high glucose reacts with Hemoglobin and other plasma protein to increase the formation of Advance glycated products may induce inflammatory process activate pro-oxidant enzymes as iNOS and NADPH oxidases (NOX2). These enzymes (iNOS and NOX2) produce ROS and RNS that damage proteins as PON 1 and uncoupling eNOS due low $\mathrm{BH}_{4}$ levels. Thus, excessive ROS production would lead to endothelial dysfunction and cardiovascular complication Furthermore, a previous research of our group has reported that M. oleifera extract exhibited potent anti-hemolytic action in a dose dependent way and the results of this study indicated that extract have a great potential to prevent both $\mathrm{HbA1C}$ and AGEs formation caused by hyperglycemia (Figure 1).

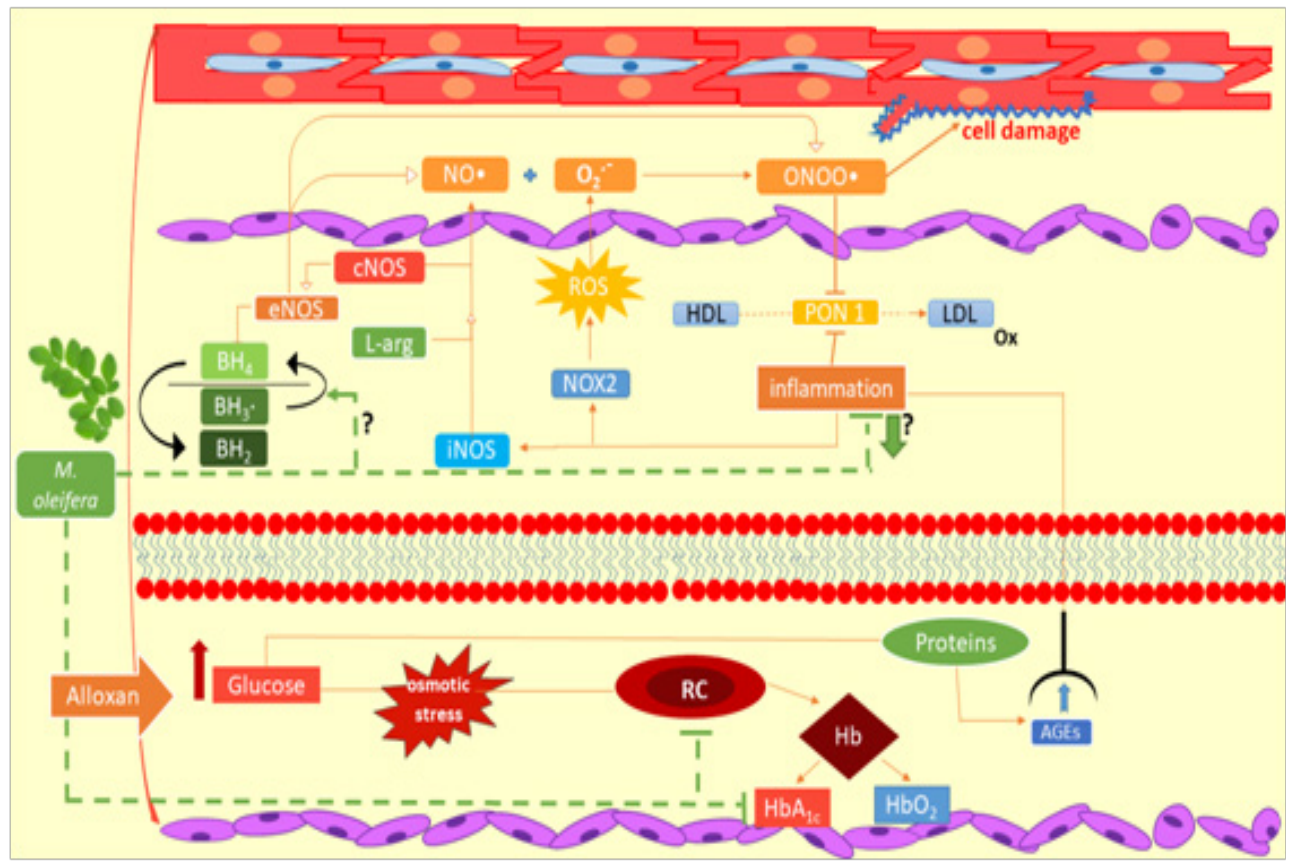

Figure I Proposed model for effect of $M$. oleifera extract on nitric oxide homeostasis in diabetic conditions. Hyperglycemia generated by Alloxan leads to increased AGEs pathway followed by NADPH oxidase and iNOS up-regulation. Accordingly, ONOO- formed by the $\mathrm{NO} / \mathrm{O}_{2}$-- reaction could then oxidize $\mathrm{BH}_{4}$ and therefore promote eNOS uncoupling. In addition, serum PONI was inactivated under oxidative stress, increasing the oxidized lipid accumulation and foam cell formation. M. oleifera leaves extract have protective effects on NO signaling, serving as antioxidants and potential inhibitors of prooxidant enzymes as NOX2 and iNOS and may be reduce macrophage foam cell formation and atherosclerosis development. 


\section{Conclusion}

This study showed that experimental diabetes alters the homeostasis of nitric oxide by increasing the activity of iNOS and that the extract of $M$. oleifera can reverse oxidative damage because it protects PON1 and the constitutive NOS activities. However, full understanding of molecular interactions of active components of M. oleifera with biological targets is required to develop a new generation of antidiabetic agents for reduction or elimination of diabetic complications.

\section{Acknowledgments}

This study was financially supported by Consejo de Ciencia y Tecnología del Estado de Durango (Cocyted, No. 12/02/18/265), Mexico. We thank Cristina Ramos-Olivas, Gladys Cithlaly EscareñoAlcala and Adriana Yazmin Nava-Sánchez which contributed importantly to the successful completion of this study. The authors are also grateful to the Mexican Moringa oleifera producers (Akuanandi) for providing all vegetal material for this study.

\section{Conflicts of interest}

The authors declare no conflict of interest

\section{References}

1. Bello Chavolla OY, Rojas-Martinez R, Aguilar-Salinas CA, et al Epidemiology of diabetes mellitus in Mexico. Nutr Rev. 2017;75(suppl $1): 4-12$.

2. Rivas-Gomez B, Almeda-Valdés P, Tussié-Luna MT, et al. Dyslipidemia in Mexico, a call for action. Rev Invest Clin. 2018;70(5):211-216.

3. Chait A, Bornfeldt KE. Diabetes and atherosclerosis: Is there a role for hyperglycemia? J Lipid Res. 2009:50 Suppl:S335-S339.

4. Aronson D, Rayfield EJ. How hyperglycemia promotes atherosclerosis: molecular mechanisms. Cardiovasc Diabetol. 2002;8:1.

5. Strijdom H, Chamane N, Lochner A. Nitric oxide in the cardiovascular system: a simple molecule with complex actions. Cardiovasc $J$ Afr. 2009;20(5):303-310

6. Farah C, Michel LYM, Balligand JL. Nitric oxide signaling in cardiovascular health and disease. Nat Rev Cardiol. 2018;15(5):292-316.

7. Förstermann U, Sessa WC. Nitric oxide synthases: regulation and function. Eur Heart J. 2012;33(7):829-837.

8. Schulz R, Nava E, Moncada S. Induction and potential biological relevance of a $\mathrm{Ca}(2+)$ independent nitric oxide synthase in the myocardium. $\mathrm{Br} J$ Pharmacol. 1992;105(3):575-580

9. Nagareddy PR, Soliman H, Lin G, et al. Selective inhibition of protein kinase $\mathrm{C}$ beta (2) attenuates inducible nitric oxide synthase-mediated cardiovascular abnormalities in streptozotocin-induced diabetic rats. Diabetes. 2009;58(10):2355-2364.

10. Marsillach J, Mackness B, Mackness M, et al. Immunohistochemical analysis of paraoxonases-1, 2, 3 expression in normal mouse tissues. Free Radic Biol Med. 2008;45(2):146-157.

11. Deakin S, Leviev I, Gomaraschi M, et al. Enzymatically active paraoxonase-1 is located at the external membrane of producing cells and released by a high affinity, saturable, desorption mechanism. $J$ Biol Chem . 2002;277(6):4301-4308

12. Mertens A, Holvoet P. Oxidized LDL and HDL: antagonists in atherothrombosis. FASEB J. 2001;15(12):2073-2084.

13. Some AA, Belemnaba L, Belemtougri RG, et al. Endothelium dependent and endothelium independent activity of ethanolic extract of Moringa oleifera Lam. (Moringaceae) on porcine coronary arteries and its underlying mechanisms of vasorelaxation. Journal Pharmacognosy and Phytochemistry. 2016;5(6):259-264.
14. Lee HJ, Jeong YJ, Lee TS, et al. Moringa fruit inhibits LPS-induced NO/ iNOS expression through suppressing the NF-KB activation in RAW264.7 cells. Am J Chin Med. 2013;41(5):1109-1123.

15. Coz-Bolaños X, Campos-Vega R, Reynoso-Camacho R, et al. Moringa infusion (Moringa oleifera) rich in phenolic compounds and high antioxidant capacity attenuate nitric oxide pro-inflammatory mediator in vitro. Ind Crop Prod. 2018;118:95-101.

16. Fard MT, Arulselvan P, Karthivashan G, et al. Bioactive extract from Moring oleifera inhibits the pro-inflammatory mediators in lipopolysaccharide stimulated macrophages. Pharmacogn Mag. 2015;11(Suppl 4):S556-S563.

17. Chumark $\mathrm{P}$, Khunawat $\mathrm{P}$, Sanvarinda $\mathrm{Y}$, et al. The in vitro and ex vivo antioxidant properties, hypolipidaemic and antiatherosclerotic activities of water extract of Moringa oleifera Lam. leaves. J Ethnopharmacol. 2008;116(3):439-446.

18. Billecke S, Draganov D, Counsell R, et al. Human serum paraoxonase (PON1) isozymes Q and R hydrolyze lactones and cyclic carbonate esters. Drug Metab Dispos. 2000;28(11):1335-1342.

19. Lu X, Guo X, Wassall CD, et al. Reactive oxygen species causes endothelial dysfunction in chronic flow overload. J Appl Physiol (1985). 1985;110(2):520-527.

20. Rajesh M, Bátkai S, Kechrid M, et al. Cannabinoid 1 receptor promotes cardiac dysfunction, oxidative stress, inflammation, and fibrosis in diabetic cardiomyopathy. Diabetes. 2012;61(3):716-727.

21. Bombicino SS, Iglesias DE, Rukavina-Mikusic IA, et al. Hydrogen peroxide, nitric oxide and ATP are molecules involved in cardiac mitochondria biogenesis in Diabetes. Free Rad Biol Med. 2017;112:267-276.

22. Khanna S, Singh GB, Khullar M. Nitric oxide synthases and diabetic cardiomyopathy. Nitric oxide. 2014;43:29-34.

23. Smith JM, Paulson DJ, Romano FD. Inhibition of nitric oxide synthase by L-NAME improves ventricular performance in STZ-diabetic rats. $J$ Mol Cell Cardiol. 1997;29(9):2393-2404.

24. Goh SY, Cooper ME. The role of advanced glycation end products in progression and complications of diabetes. J Clin Endocrinol Metab. 2008;93(4):1143-1152.

25. Cohen MP. Intervention strategies to prevent pathogenetic effects of glycated albumin. Arch Biochem Biophys. 2003;419(1):25-30.

26. Candiloros H, Muller S, Ziegler O, et al. Role of albumin glycation on the erythrocytes aggregation: an in vitro study. Diabet Med. 1996;13(7):646-650

27. Wautier JL, Zoukorian C, Chappey O, et al. Receptor-mediated endothelial cell dysfunction in diabetic vasculopathy. Soluble receptor for advanced glycation end products blocks hyperpermeability in diabetic rats. $J$ Clin Invest. 1996;97(1):238-243.

28. Inoguchi T, Li P, Umeda F, et al. High glucose level and free fatty acid stimulate reactive oxygen species production through protein kinase $\mathrm{C}$ dependent activation of $\mathrm{NAD}(\mathrm{P}) \mathrm{H}$ oxidase in cultured vascular cells. Diabetes. 2000;49(11):1939-1945.

29. Zhang ML, Zheng B, Tong F, et al. iNOS-derived peroxynitrite mediates high glucose-induced inflammatory gene expression in vascular smooth muscle cells through promoting KLF5 expression and nitration. Biochim Biophys Acta Mol Basis Dis. 2017;1863(11):2821-2834.

30. Hishikawak, Lüscher TF. Felodipine inhibits free-radical production by cytokines and glucose in human smooth muscle cells. Hypertension. 1998;32(6):1011-1015.

31. Muniyappa R, Xu R, Ram JL, et al. Inhibition of Rho protein stimulates iNOS expression in rat vascular smooth muscle cells. Am J Physiol Heart Circ Physiol. 2000;278(6):H1762-H1768.

32. Pacheco ME, Beltrán A, Redondo J, et al. High glucosa enhances inducible nitric oxide synthase expresión. Role of protein kinase C betall. Eur J Pharmacol. 2006;538(1-3):115-123. 
33. Crabtree MJ, Tatham AL, Al-Wakeel Y, et al. Quantitative regulation of intracellular endothelial nitric-oxide synthase (eNOS) coupling by both tetrahydrobiopterin-eNOS stoichiometry and biopterin redox status: insights from cells with tet-regulated GTP cyclohydrolase I expression. $J$ Biol Chem. 2009;284(2):1136-1144.

34. Meininger CJ, Marinos RS, Hatakeyama K, et al. Impaired nitric oxide production in coronary endothelial cells of the spontaneously diabetic BB rat is due to Tetrahydrobiopterin deficiency. Biochem J. 2000;349(Pt 1):353-356.

35. Crabtree MJ, Brixey R, Batchelor $\mathrm{H}$, et al. Integrated redox sensor and effector functions for tetrahydrobiopterin- and glutathionylationdependent endothelial nitric-oxide synthase uncoupling. $J$ Biol Chem. 2013;288(1):561-569.

36. Aviram M, Rosenblat M. Paraoxonase 1, 2, 3, oxidative stress, and macrophage foam cell formation during atherosclerosis development. Free Radic Biol Med. 2004;37(9):1304-1316.

37. Draganov DI, Stetson PL, Watson CE, et al. Rabbit serum paraoxonase 3 (PON3) is a high-density lipoprotein-associated lactonase and protects low density lipoprotein against oxidation. $J$ Biol Chem. 2000;275(43):33435-33442.
38. Mackness B, Durrington PN, Boulton AJ, et al. Serum paraoxonase activity in patients with type I diabetes compared to healthy controls. Eur J Clin Invest. 2002;32(4):259-264.

39. Mackness B, McElduff P, Mackness MI. The paraoxonase-2-310 polymorphism is associated with the presence of microvascular complications in diabetes mellitus. J Intern Med. 2005;258(8):363-368.

40. Zhu Y, Huang X, Zhang Y, et al. Anthocyanin Supplementation Improves HDL-Associated Paraoxonase 1 Activity and Enhances Cholesterol Efflux Capacity in Subjects with Hypercholesterolemia. J Clin Endocrinol Metab. 2014;99(2):561-569.

41. Farid AS, Horii Y. Modulation of paraoxonases during infections diseases and its potential impact on atherosclerosis. Lipids Health Dis. 2012;11:92.

42. Atrahimovich D, Vaya J, Khatib S. The effects and mechanism of flavonoidrePON1 interactions. Structure-activity relationship study. Bioorg Med Chem. 2013;21(11):3348-3355. 